\title{
Kidney dysfunction, systemic inflammation and mental well-being in elderly post- myocardial infarction patients
}

\author{
Rick H. M. Heeres ${ }^{1 *} \mathbb{D}$, Ellen K. Hoogeveen ${ }^{2}$, Johanna M. Geleijnse ${ }^{3}$, Janette de Goede ${ }^{3}$, Daan Kromhout ${ }^{3}$ \\ and Erik J. Giltay ${ }^{1}$
}

\begin{abstract}
Background: The aim was to investigate whether mild kidney dysfunction and low-grade inflammation in postmyocardial infarction patients are independently associated with markers of mental well-being (i.e. depressive and apathy symptoms, and dispositional optimism).

Methods: In post-myocardial infarction patients, kidney function was assessed by estimated glomerular filtration rate (eGFR) calculated from the combined CKD-EPI formula based on serum levels of both creatinine and cystatine C. Systemic inflammation was assessed using high sensitivity C-reactive protein (hs-CRP) levels. The 15-item Geriatric Depression Scale (GDS-15), the 3-item apathy subscale and the 4-item optimism questionnaire (4Q) were used to measure mental well-being and were analyzed using linear multivariable regression analysis.

Results: Of the 2355 patients, mean age was 72.3 (range 63-84) years and $80.1 \%$ were men. After multivariable adjustment, a poorer kidney function was associated with more depressive symptoms $(\beta=-0.084, p<0.001)$, more apathy symptoms $(\beta=-0.101, p<0.001)$, and less dispositional optimism $(\beta=0.072, p=0.002)$. Moreover, higher levels of hs-CRP were associated with more depressive symptoms ( $\beta=0.051, p=0.013$ ), more apathy symptoms ( $\beta=0.083, p<0.001)$ and less dispositional optimism $(\beta=-0.047 p=0.024)$. Apathy showed the strongest independent relation with both low eGFR and high hs-CRP.

Conclusions: In post-myocardial infarction patients, impaired kidney function and systemic inflammation showed a stronger association with apathy than with depressive symptoms and dispositional optimism.
\end{abstract}

Keywords: Kidney dysfunction, Systemic inflammation, Apathy, Depressive symptoms, Dispositional optimism, Myocardial infarction

\section{Background}

Depressive symptoms in coronary heart disease (CHD) patients are associated with an increase in cardiac morbidity and mortality [1]. The prevalence of major depressive disorder (MDD) in post-myocardial infarction patients is estimated at about 20\% [2]. CHD is also associated with an increased occurrence of chronic kidney disease (CKD) [3], which may further contribute to the development of depressive symptoms [4-6]. It is well established that end-stage renal disease (ESRD) is

\footnotetext{
* Correspondence: heeresrick@gmail.com

${ }^{1}$ Department of Psychiatry, Leiden University Medical Center, Postbus 9600, 2300, RC, Leiden, Netherlands

Full list of author information is available at the end of the article
}

associated with a poor quality of life and depressive symptoms, whereas this has not been thoroughly investigated for earlier stages of CKD. Patients with ESRD also have a prevalence of about $20 \%$ for MDD [7]. Moreover, as an inflammatory reaction is common in patients with ESRD, it is hypothesized that inflammation partly links ESRD to depressive symptoms $[8,9]$. Systemic low-grade inflammation is present in patients with CKD, as well as in CHD, and may mediate the increased risk of depressive symptoms and apathy [10-13].

In three large cross-sectional studies, including 3700 to $\geq 28,000$ patients [14-16], those with severe CKD (i.e. with an estimated glomerular filtration rate [eGFR] $<30 \mathrm{ml} / \mathrm{min} / 1.73 \mathrm{~m}^{2}$ ) had more depressive symptoms 
than those without CKD $\left(\mathrm{eGFR} \geq 60 \mathrm{ml} / \mathrm{min} / 1.73 \mathrm{~m}^{2}\right)$. However, in only one of those studies (that included patients with diabetes) did the increased risk of depressive symptoms remain significant after adjustment for all relevant covariates [15]. Whether or not less severe forms of impaired kidney function $\left(30 \mathrm{ml} / \mathrm{min} / 1.73 \mathrm{~m}^{2}\right.$ or higher) are associated with more depressive symptoms is still largely unknown. Moreover, the largest study that analyzed the continuous relation between eGFR and depressive symptoms found no significant associations [14]. Moreover, we are aware of only two studies on the association between CKD and depressive symptoms in cohorts of cardiac patients. In 374 patients suffering from congestive heart failure, Hedayati et al. found that those with severe CKD scored significantly higher on depressive symptoms [17]. In contrast, among 967 CHD patients, Odden et al. found no significant difference in depressive symptoms between patients with and without CKD [18].

A low-grade pro-inflammatory state is common in patients with CHD, exemplified by higher levels of serum C-reactive protein (CRP) [13]. A positive association between inflammatory markers and depressive symptoms is also well established in persons without somatic illness [19]. However, less is known about these associations in CHD patients. Among three studies that included from 71 to almost 1000 CHD patients [20-22], only the smaller study found a significantly increased CRP level in depressed CHD patients [22], whereas the two larger studies found no significant relation [20, 21]. In another study, when examining the linear relation between increasing CRP level and depressive symptoms, higher levels of CRP showed a significant association with more depressive symptoms; however, this association did not persist after adjustment for covariates [23].

The association between depressive symptoms and CHD has been called into question by recent crosssectional and prospective studies in community-dwelling elderly [24-26]. Apathy, rather than depressive symptoms, was significantly associated with a higher incidence of CHD and other cardiovascular diseases. Apathy is a syndrome of primary motivational loss which manifests itself in a decrease in goal-directed cognition, emotion and behavior [27]. Two cross-sectional studies (including 1810 and 3534 subjects, respectively) also found that higher levels of CRP were significantly associated with more apathy $[25,26]$. However, two longitudinal studies found no such association in 225 and 1015 elderly patients, respectively $[28,29]$.

The Alpha Omega Trial provided us with the opportunity to perform a cross-sectional analysis of mental wellbeing in post-myocardial infarction patients with a kidney function that ranged from normal to non-dialysisdependent CKD stage 5. We aimed to investigate whether mild kidney dysfunction and low-grade inflammation were independently associated with markers of mental well-being i.e. depressive symptoms, apathy symptoms, and dispositional optimism. Dispositional optimism is defined as generalized positive outcome expectancies and a future orientation with trait-like mental properties [30].

Whereas previous studies used only creatinine levels to assess the eGFR, we included both creatinine and cystatin-C (CysC) levels to more accurately estimate kidney function [31], as well as high-sensitivity CRP (hs-CRP) as a measure of systemic inflammation.

\section{Methods}

\section{Patients}

The Alpha Omega Trial was a multicenter, double-blind, placebo-controlled trial conducted between 2002 and 2009 on the effect of low doses of n-3 fatty acids on cardiovascular events, described in detail elsewhere [32, 33]. The cohort consisted of 4837 free-living Dutch postmyocardial infarction patients aged $60-80$ years, receiving state-of-the-art antihypertensive, antithrombotic and lipid-modifying drug treatment at baseline. Patients were randomly assigned to one of four trial margarines and were followed-up for 40 months (ClinicalTrials.gov no. NCT00127452). Blood samples were taken at baseline and after 40 months in patients randomized before August 2005 (i.e. $48 \%$ of the cohort, owing to financial constraints). Mental well-being questionnaires were administered at 40 months.

For the present cross-sectional study we used the 40month follow-up data of 2355 (48.7\% of 4837) patients who supplied blood samples and also completed the mental well-being questionnaires at 40 months [33].

\section{Assessment of psychological measures}

Depressive symptoms were assessed using the 15-item Geriatric Depression Scale (GDS-15) [34]. This selfadministered questionnaire contains 15 yes/no questions and excludes certain somatic symptoms which might be due to medical illness. Higher scores (range 0-15) indicate more depressive symptoms during the past week. The GDS-15 is a reliable and well-validated measure of depressive symptoms in elderly medical patients [35]. For computation of the GDS-15 score, two missing items were allowed and were subsequently imputed with the mean of the remaining 13 or 14 items $(n=206$ of $2355,8.7 \%$ ).

Apathy was assessed using the GDS apathy-3 subscale. This is a subscale of the GDS-15 which consists of the following three questions: "Have you dropped many of your activities and interests?", "Do you prefer to stay at home, rather than going out and doing new things?", and "Do you feel full of energy?" Compared with the 14-item 
apathy scale [36], the GDS apathy-3 subscale has a sensitivity of $69 \%$ and a specificity of $85 \%$ [24]. For computation of the GDS apathy-3 subscale, one missing item was allowed and was subsequently imputed with the mean of the remaining two items ( $n=73$ of $2355,3.1 \%)$.

Dispositional optimism was assessed using the $4 \mathrm{Q}$ which centers around a focus on the future and is more closely related to life engagement, vitality, and feelings of having a purpose in life. In the Netherlands, the $4 \mathrm{Q}$ was used as part of a national 'life situation' survey by the Central Bureau of Statistics in 1976 and 1982. The 4Q consists of the following four items "I still expect much from life," "I do not look forward to the years to come," "My days seem to pass by slowly," and "I am still full of plans" (our translations). The response format was a 3point scale of frequency: "fully in agreement" (score, 0), "partially in agreement" (score, 1), and "not in agreement" (score, 2). The additional answer category "do not know" was also coded as the midpoint (score, 1). The scores of two questions needed to be reverse coded, so that higher scores indicated greater optimism. Higher scores (range 0-8) indicated higher dispositional optimism. The 4Q shows moderate internal consistency and has clinical predictive value for cardiovascular mortality [37]. For computation of the $4 \mathrm{Q}$ score, one missing item was allowed and was subsequently imputed with the mean of the remaining 3 items ( $n=21$ of $2355,0.9 \%$ ).

\section{Assessment of biological measures}

Blood handling procedures for the Alpha Omega Trial are described in detail elsewhere [38]. In brief, blood samples were obtained at the patient's home or at the hospital, packaged in sealed envelopes and sent via standard postal service to a central laboratory.

Serum creatinine and $\mathrm{CysC}$ were measured from stored blood samples in a central laboratory [31]. Serum creatinine was measured by the modified kinetic Jaffé method (Dimension Vista 1500 Analyzer; Siemens). We calibrated directly to the standard supplied by the manufacturer from the National Institute of Standards and Technology Standard Reference Material, and a postcalibration correction factor was applied [31]. Intra- and inter-assay variations for low creatinine (mean $=0.8 \mathrm{mg} / \mathrm{dl}$ ) were 1.8 and $2.9 \%$, respectively, and for high creatinine $($ mean $=3.9 \mathrm{mg} / \mathrm{dl})$ they were 0.8 and $2.2 \%$, respectively. Serum creatinine values $<0.6 \mathrm{mg} / \mathrm{dl}$ were unreliable (owing to technical failure or analytical disturbance; $n=82$ ) and, therefore, not reported in accordance with the Standard Operating Procedure of the central laboratory.

Serum CysC was measured by means of a particleenhanced immune nephelometric assay (NLatex Cystatin C, Dimension Vista 1500 Analyzer; Siemens). We used calibrators and assays of the same lot code, which was stable (no downward drift). CysC was calibrated directly using the standard supplied by the manufacturer (traceable to the International Federation of Clinical Chemistry Working Group for Standardization of Serum Cystatin C) [39]. The analytical measurement range of $\mathrm{Cys} C$ was 0.23-8.00 $\mathrm{mg} / \mathrm{L}$. Intra- and inter-assay variations for low CysC $($ mean $=1.00 \mathrm{mg} / \mathrm{L})$ were 1.3 and $4.2 \%$, respectively, and for high CysC (mean $=1.75 \mathrm{mg} / \mathrm{L}$ ) they were 2.9 and $2.8 \%$, respectively.

We estimated GFR using the combined creatinineCysC-based Chronic Kidney Disease Epidemiology Collaboration (CKD-EPI) equation from 2012, taking into account age, sex, and race [31]. In addition, we used the CysC-based eGFR from the CKD-EPI equation from 2012 as well as the creatinine based eGFR from the CKD-EPI equation from 2009 separately [31].

Serum hs-CRP was measured in stored serum samples (Nephelometric, Deimension Vista 1500 analyzer, Siemens). Intra- and inter-assay variation for low hsCRP (mean $=1.0 \mathrm{mg} / \mathrm{l}$ ) was 2.1 and $1.6 \%$, respectively, and for high hs-CRP (mean $=2.8 \mathrm{mg} / \mathrm{l}$ ) this was 2.0 and $2.4 \%$, respectively.

\section{Data collection}

Patients were interviewed and physically examined by trained research nurses at home or in the hospital. Information on demographic variables (i.e., age, sex, ethnicity, educational level), lifestyle habits (i.e. smoking status, alcohol use, and physical activity), medication use and medical history (i.e., time since myocardial infarction, and history of stroke) were collected by self-administered questionnaires, as previously described in detail [33]. Medication was coded according to the Anatomical Therapeutic Chemical Classification System (ATC). Anthropometric measures were measured, body mass index (BMI) was computed $\left(\mathrm{kg} / \mathrm{m}^{2}\right)$ and blood pressure was measured. Diabetes mellitus was considered present in the case of a self-reported physician diagnosis, use of antidiabetic drugs, and/or elevated blood glucose.

\section{Data analysis}

Patients were divided according to eGFR $\leq 60$ or $\geq 60 \mathrm{ml} /$ min per $1.73 \mathrm{~m}^{2}$ and also divided according to the hs-CRP level $(<3 \mathrm{mg} / \mathrm{l}$ and $\geq 3 \mathrm{mg} / \mathrm{l})$ based on the clinical cut-off point of $3 \mathrm{mg} / \mathrm{l}$. Patient characteristics are listed in Table 1; data are presented as median (interquartile range), mean $( \pm \mathrm{SD})$, or number (percentage of the total), where appropriate.

Four eGFR categories were defined based on eGFR; $\geq$ $90,60-89,30-59$, and $<30 \mathrm{ml} / \mathrm{min} / 1.73 \mathrm{~m}^{2}$, using the CKD classification as proposed by the National Kidney Foundation-Kidney Disease Outcomes Quality Initiative (KDOQI) guidelines [40]. Clinical cut-points of CRP for risk of future cardiovascular events were used; levels $<1$, $1-3,3-5$, and $\geq 5 \mathrm{mg} / \mathrm{L}$ represent very low, low, mildly 
Table 1 Characteristics of the cohort of 2355 post-myocardial infarction patients according to creatinine-cystatin C-based eGFR and serum CRP level

\begin{tabular}{|c|c|c|c|c|c|c|}
\hline & \multicolumn{3}{|c|}{ Creatinine-Cystatin C-based eGFR, ml/min/1.73 m² } & \multicolumn{3}{|c|}{ C-reactive protein levels, mg/L } \\
\hline & $\begin{array}{l}\geq 60 \\
(n=1750)\end{array}$ & $\begin{array}{l}<60 \\
(n=605)\end{array}$ & $P$-value & $\begin{array}{l}<3 \\
(n=1564)\end{array}$ & $\begin{array}{l}\geq 3 \\
(n=791)\end{array}$ & $P$-value \\
\hline Age, years & $71.2 \pm 5.04$ & $75.4 \pm 5.3$ & $<0.001$ & $72.0 \pm 5.3$ & $72.7 \pm 5.6$ & 0.004 \\
\hline Men, No. (\%) & $1465(83.7 \%)$ & $422(69.8 \%)$ & $<0.001$ & $1291(82.5 \%)$ & $596(75.3 \%)$ & $<0.001$ \\
\hline Higher education ${ }^{a}, n(\%)$ & 767 (44.0\%) & $238(39.7 \%)$ & 0.064 & $715(45.9 \%)$ & $290(36.9 \%)$ & $<0.001$ \\
\hline Body mass index ${ }^{\mathrm{b}}, \mathrm{kg} / \mathrm{m}^{2}$ & $27.6 \pm 3.6$ & $28.1 \pm 4.1$ & 0.003 & $27.3 \pm 3.4$ & $28.6 \pm 4.15$ & $<0.001$ \\
\hline Physically active ${ }^{c}, n(\%)$ & $389(22.3 \%)$ & $87(14.5 \%)$ & $<0.001$ & $340(21.8 \%)$ & $136(17.3 \%)$ & 0.010 \\
\hline Current smoker, $n(\%)$ & $267(15.3 \%)$ & $83(13.8 \%)$ & 0.363 & $184(11.8 \%)$ & $166(21.0 \%)$ & $<0.001$ \\
\hline Alcohol use $\geq 1$ glass/week, $n$ (\%) & $1286(73.6 \%)$ & $360(59.9 \%)$ & $<0.001$ & $1135(72.8 \%)$ & $510(64.8 \%)$ & $<0.001$ \\
\hline Antidepressant use, $n(\%)$ & $78(4.5 \%)$ & $40(6.6 \%)$ & 0.036 & $67(4.3 \%)$ & $51(6.4 \%)$ & 0.023 \\
\hline Time since myocardial infarction, years & $4.5 \pm 3.1$ & $4.7 \pm 3.4$ & 0.110 & $4.5 \pm 3.2$ & $4.7 \pm 3.2$ & 0.117 \\
\hline Self-reported history of stroke, $n(\%)$ & $94(5.4 \%)$ & $58(9.7 \%)$ & $<0.001$ & $84(5.4 \%)$ & $68(8.7 \%)$ & 0.003 \\
\hline Diabetes $^{\mathrm{d}}, n(\%)$ & $93.1(22.3 \%)$ & $188(31.1 \%)$ & $<0.001$ & $375(24.0 \%)$ & $204(25.8 \%)$ & 0.334 \\
\hline Systolic blood pressure, $\mathrm{mmHg}$ & $142.9 \pm 20.5$ & $141.6 \pm 23.7$ & 0.188 & $143.4 \pm 20.9$ & $140.9 \pm 22.1$ & 0.006 \\
\hline \multicolumn{7}{|l|}{ Use of cardiovascular medication ${ }^{\mathrm{e}}, n(\%)$} \\
\hline Antithrombotic agents & $1713(97.9 \%)$ & $584(96.5 \%)$ & 0.063 & $1529(97.8 \%)$ & $768(97.1 \%)$ & 0.322 \\
\hline Blood pressure lowering drugs & $1729(98.8 \%)$ & $591(97.7 \%)$ & 0.051 & $1537(98.3 \%)$ & $783(99.0 \%)$ & 0.176 \\
\hline Statins & $1553(88.7 \%)$ & $513(84.8 \%)$ & 0.011 & $1399(89.5 \%)$ & $667(84.3 \%)$ & $<0.001$ \\
\hline High-sensitivity C-reactive protein, mg/L & $1.42(0.71-3.15)$ & $3.33(1.27-6.91)$ & $<0.001$ & $1.01(0.61-1.72)$ & $5.66(4.04-8.83)$ & $<0.001$ \\
\hline Serum creatininef, mg/dl & $0.96 \pm 0.18$ & $1.54 \pm 0.61$ & $<0.001$ & $1.05 \pm 0.33$ & $1.22 \pm 0.56$ & $<0.001$ \\
\hline Serum cystatin C, mg/L & $0.89 \pm 0.13$ & $1.41 \pm 0.42$ & $<0.001$ & $0.96 \pm 0.24$ & $1.15 \pm 0.42$ & $<0.001$ \\
\hline
\end{tabular}

Data are presented as median (interquartile range), mean $( \pm S D)$ or number (percentage of the total)

${ }^{a}$ Defined as higher vocational education, college or university

body mass index was calculated as weight in kilograms divided by height in meters squared

'Defined as $\geq 3$ Metabolic Equivalent Tasks (MET) during $>5$ days/week

${ }^{d}$ Diabetes was considered to be present if a patient reported having received the diagnosis from a physician, was taking antidiabetic drugs, or had an elevated plasma glucose level ( $\geq 126 \mathrm{mg} / \mathrm{dl}$ in the case of patients who had fasted more than $4 \mathrm{~h}$ or $\geq 200 \mathrm{mg} / \mathrm{dl}$ in the case of non-fasting patients)

${ }^{\mathrm{e}}$ Antithrombotic agents ATC code B01. Blood pressure lowering drugs: ATC codes C02, C03, C07, C08 and C09. Statins: ATC code C10AA

fTo convert the values for creatinine to $\mu \mathrm{mol} / \mathrm{L}$, multiply by 88.40

increased, and moderately to severely increased levels, respectively [41].

Because plasma concentrations of hs-CRP showed a positively skewed distribution, levels were $\log _{e}$ transformed before analyses to yield a normal distribution. Mean GDS-15 and 4Q scores \pm standard error as well as median (25th and 75th percentiles $\left[\mathrm{P}_{25}, \mathrm{P}_{75}\right]$ ) were calculated per eGFR and hs-CRP category. The Pearson's correlation coefficient was used to assess the association between the 12-item GDS depression score (excluding the 3 apathy items) and the 3-item GDS apathy score, as well as the association between the total GDS total score and the 4Q optimism score. The Pearson's correlation coefficient was calculated between the original optimism score and an optimism score in which all items with a "don't know" answer were imputed with the mean of the remaining items. A correlation coefficient of 0.95 $(P<0.001)$ was found in the 463 participants with at least one "don't know" answer, suggesting that "don't know" coded as the midpoint was unlikely to have distorted the total optimism score. Analysis of covariance (ANCOVA) was used to determine significance for linear trend over the four categories of eGFR and CRP levels. All adjusted analyses were corrected for the 4 randomized groups (because, in the original trial, patients were treated during 40 months with either n-3 fatty acids or placebo) [33].

Models were specified for multivariable testing to adjust for possible confounders. Model 1 adjusted for age, sex, level of education, and the 4 randomized treatment groups; model 2 additionally adjusted for BMI, smoking status, alcohol use, antidepressant use, time since myocardial infarction, stroke and diabetes; model 3 was the full model and additionally adjusted for the other possible predictor variables (either creatinine-CysC-based eGFR or hs-CRP level) to determine the independent association of eGFR and hs-CRP with depressive and apathy symptoms, and dispositional optimism. Moreover, we included all three mental well-being parameters (12-item GDS depression score (excluding the 3 apathy 
items), 3-item GDS apathy score and the 4Q optimism score) into one statistical model as independent variables with eGFR or hs-CRP as the dependent variables. Linear associations were tested using univariate regression analysis. Analyses were stratified for gender, and gender $\times$ predictor interaction terms were added to the full model 3 to test whether associations showed a significant difference between women and men.

Two additional sensitivity analyses were performed in which, first, we excluded all 221 participants with any missing items on any of the mental well-being questionnaires and, second, we also excluded all 463 participants with a "don't know" answer on the 4Q as well as the 221 participants with any missing items, leaving 1723 participants available for the analyses.

All analyses were conducted using IBM SPSS statistics 20.0 (SPSS, Inc., Chicago, IL, USA).

\section{Results}

In the total group of 2355 patients, mean age was 72.3 years; $80.1 \%$ were men and $99.8 \%$ were Caucasian. Of all patients, 1750 (74\%) had an eGFR $\geq 60 \mathrm{ml} / \mathrm{min} /$ $1.73 \mathrm{~m}^{2}$. The remaining $605(26 \%)$ patients with an eGFR $<60 \mathrm{ml} / \mathrm{min} / 1.73 \mathrm{~m}^{2}$ were more often female, less physically active, used less alcohol, more often had diabetes, and had a higher mean level of hs-CRP than those with an eGFR $\geq 60 \mathrm{ml} / \mathrm{min} / 1.73 \mathrm{~m}^{2}$. There were 1564 (66\%) patients with a low hs-CRP level of $\leq 3 \mathrm{mg} / \mathrm{L}$; the 791 patients with a high hs-CRP level were more often female, more often smoked, and used less alcohol than those with low hs-CRP (Table 1).

The Pearson's correlation coefficient showed that the association between the apathy score and the 12-item GDS depression score (excluding the 3 apathy items) was only 0.42 . The complete 15 -item GDS total score and the $4 \mathrm{Q}$ optimism score were inversely associated with a correlation coefficient of -0.63 .

\section{Kidney function and mental well-being}

In the fully adjusted model, categories with lower eGFR showed a significant association with more depressive symptoms. Patients with an eGFR $<60 \mathrm{ml} / \mathrm{min} / 1.73 \mathrm{~m}^{2}$ had significantly more depressive symptoms (mean GDS-15 score 2.70) than patients with an eGFR $\geq 60 \mathrm{ml} /$ $\mathrm{min} / 1.73 \mathrm{~m}^{2}$ (mean GDS-15 score 1.80). Categories with lower eGFR showed a significant association with more apathy symptoms. Patients with an eGFR $\geq 90 \mathrm{ml} / \mathrm{min} /$ $1.73 \mathrm{~m}^{2}$ showed significantly less apathy than patients with an eGFR of $60-89 \mathrm{ml} / \mathrm{min} / 1.73 \mathrm{~m}^{2}$. Categories with lower eGFR were also significantly associated with less dispositional optimism (Table 2).

Likewise, linear regression analyses showed that a lower level of eGFR was linearly associated with more depressive symptoms $(\beta=-0.084, p<0.001)$ and with less dispositional optimism ( $\beta=0.072, p=0.002$; Table 3 ). The association between a lower level of eGFR and more apathy symptoms was stronger $(\beta=-0.101 ; p<0.001)$. All these associations persisted after additional adjustment for hsCRP. Interaction terms showed that relations were similar in women and men $(p>0.30$, for all three interaction terms). When including all three mental well-being parameters into one statistical model as independent variables with eGFR as the dependent variable, apathy $(\beta=-0.066, p=0.001)$ was the only significant correlate, whereas dispositional optimism $(p=0.12)$ and the 12 -item GDS depression score $(p=0.99)$ were no longer significant. Moreover, when we excluded the 48 participants with a eGFR $<30 \mathrm{ml} / \mathrm{min} / 1.73 \mathrm{~m}^{2}$ from the analyses, the eGFR was still inversely associated with apathy $(\beta=-0.054, p=0.01)$, independently from CRP and all other covariates.

\section{C-reactive protein and mental well-being}

In the fully adjusted model, categories of higher hs-CRP serum level showed a significant association with more depressive symptoms, more apathy symptoms and less dispositional optimism (Table 2). Linear regression analysis also showed that a higher level of hs-CRP was significantly associated with more depressive symptoms $(\beta=0.051 ; p=0.013)$ more apathy symptoms $(\beta=0.083$; $p<0.001)$ and less dispositional optimism $(\beta=-0.047$; $p=0.024)$. However, after additional adjustment for the eGFR, only the association with apathy remained significant $(\beta=-0.065 ; p=0.002)$. In Fig. 1 , the adjusted relationship with categories of hs-CRP seem to depict a threshold effect for the CRP level of $\geq 7$. Moreover, when including all three mental well-being parameters into one statistical model as independent variables with the log-transformed CRP level as the dependent variable, apathy $(\beta=0.082$, $p<0.001)$ was the only significant correlate, whereas dispositional optimism $(p=0.40)$ and the 12-item GDS depression score $(p=0.36)$ were not.

When testing for interaction, the interaction term for gender $\times$ hs-CRP was significant for depression $(\beta=0.129$, $p=0.008)$, not significant for apathy $(\beta=0.076, p=0.12)$, and of borderline significance for optimism $(\beta=-0.088$, $p=0.074)$. In subsequent stratified analyses, associations with depressive symptoms $(\beta=0.064, p=0.007)$, apathy symptoms $(\beta=0.079, p=0.001)$ and optimism $(\beta=-0.059$ $p=0.014$ ) were stronger in men than in women.

Sensitivity analysis in 2134 and 1723 participants (i.e. excluding those with missing values and "don't know" answer category) showed that the relationship between eGFR and CRP on the one hand, and depressive/apathy symptoms and optimism on the other, were hardly affected. In particular, there was no attenuation as, in the adjusted model, the relationship with CRP increased in strength in the sample of 1723 participants. 
Table 2 Categories of creatinine-cystatin C-based eGFR and serum level CRP in relation to depressive and apathy symptoms, and dispositional optimism in 2355 post-myocardial infarction patients

\begin{tabular}{|c|c|c|c|c|c|c|}
\hline $\begin{array}{l}\text { Creatinine-cystatin C-based } \\
\text { eGFR, } \mathrm{ml} / \mathrm{min} / 1.73 \mathrm{~m}^{2}\end{array}$ & $\begin{array}{l}\geq 90 \\
(n=517)\end{array}$ & $\begin{array}{l}60-89 \\
(n=1233)\end{array}$ & $\begin{array}{l}30-59 \\
(n=552)\end{array}$ & $\begin{array}{l}<30 \\
(n=53)\end{array}$ & Test statistic & $P$-value for trend \\
\hline \multicolumn{7}{|l|}{ Depressive symptoms: } \\
\hline Median $\left(P_{25}, P_{75}\right)$ & $1(0-2)$ & $1(0-3)$ & $2(1-4)$ & $2(1-4)$ & & \\
\hline crude & $1.54(\mathrm{SE} 0.08)^{\mathrm{a}}$ & $1.92(\mathrm{SE} 0.06)^{\mathrm{b}}$ & $2.68(\mathrm{SE} 0.12)^{\mathrm{C}}$ & $3.12(\operatorname{SE~} 0.41)^{c}$ & $F(1,2351)=80.6$ & $<0.001$ \\
\hline model 1 & $1.72(\mathrm{SE} 0.10)^{\mathrm{a}}$ & $1.94(\mathrm{SE} 0.06)^{\mathrm{a}}$ & $2.47(\mathrm{SE} 0.10)^{\mathrm{b}}$ & $2.90(\mathrm{SE} 0.31)^{\mathrm{b}}$ & $F(1,2335)=31.4$ & $<0.001$ \\
\hline model 2 & $1.79(\text { SE } 0.10)^{a}$ & $1.95(\mathrm{SE} 0.06)^{\mathrm{a}}$ & $2.34(\mathrm{SE} 0.10)^{\mathrm{b}}$ & $2.67(\mathrm{SE} 0.31)^{\mathrm{b}}$ & $F(1,2280)=17.4$ & $<0.001$ \\
\hline \multicolumn{7}{|l|}{ Apathy subscale: } \\
\hline Median $\left(P_{25}, P_{75}\right)$ & $0(0-1)$ & $1(0-2)$ & $1(0-2)$ & $2(1-2.5)$ & & \\
\hline crude & $0.74(\text { SE } 0.04)^{a}$ & $0.97(\mathrm{SE} 0.03)^{\mathrm{b}}$ & $1.29(\mathrm{SE} 0.04)^{c}$ & $1.64(\text { SE 0.14) })^{d}$ & $F(1,2351)=108.5$ & $<0.001$ \\
\hline model 1 & $0.85(\text { SE } 0.04)^{\mathrm{a}}$ & $0.98(\text { SE } 0.03)^{b}$ & $1.18(\mathrm{SE} 0.04)^{\mathrm{C}}$ & $1.47(\mathrm{SE} 0.14)^{d}$ & $F(1,2335)=36.1$ & $<0.001$ \\
\hline model 2 & $0.87\left(\right.$ SE 0.04) ${ }^{\mathrm{a}}$ & $0.99($ SE 0.03) & $1.12(\mathrm{SE} 0.04)^{c}$ & $1.38(\mathrm{SE} 0.13)^{c}$ & $F(1,2280)=20.4$ & $<0.001$ \\
\hline \multicolumn{7}{|l|}{ Dispositional optimism: } \\
\hline Median $\left(P_{25}, P_{75}\right)$ & $7(6-8)$ & $7(6-8)$ & $6(5-7)$ & $6(4-7)$ & & \\
\hline crude & $6.71(\mathrm{SE} 0.06)^{a}$ & $6.38(\text { SE 0.04) })^{b}$ & $5.82($ SE 0.08) & $5.59(\operatorname{SE} 0.25)^{\mathrm{c}}$ & $F(1,2351)=94.7$ & $<0.001$ \\
\hline model 1 & $6.49($ SE 0.07) & $6.36(\text { SE 0.04) })^{a}$ & $6.04($ SE 0.07) & $5.91(\mathrm{SE} 0.22)^{\mathrm{b}}$ & $F(1,2335)=21.6$ & $<0.001$ \\
\hline model 2 & 6.46 (SE 0.07) & 6.35 (SE 0.04) & 6.08 (SE 0.07) & 6.01 (SE 0.22) & $F(1,2280)=14.2$ & $<0.001$ \\
\hline C-reactive protein levels, mg/L & $\begin{array}{l}<1 \\
(n=766)\end{array}$ & $\begin{array}{l}1-3 \\
(n=798)\end{array}$ & $\begin{array}{l}3-5 \\
(n=330)\end{array}$ & $\begin{array}{l}\geq 5 \\
(n=461)\end{array}$ & & $P$-value for trend \\
\hline \multicolumn{7}{|l|}{ Depressive symptoms: } \\
\hline Median $\left(P_{25}, P_{75}\right)$ & $1(0-3)$ & $1(0-3)$ & $1(0-3)$ & $2(1-3.7)$ & & \\
\hline crude & $1.86(\mathrm{SE} 0.08)^{\mathrm{a}}$ & $1.87\left(\mathrm{SE} \mathrm{0.07)^{ \textrm {a } }}\right.$ & $2.15(\mathrm{SE} 0.13)^{\mathrm{a}}$ & $2.55(\mathrm{SE} 0.12)^{\mathrm{b}}$ & $F(1,2351)=28,34$ & $<0.001$ \\
\hline model 1 & $1.92($ SE 0.08) & $1.88\left(\mathrm{SE} \mathrm{0.08)^{ \textrm {a } }}\right.$ & $2.12($ SE 0.12) & $2.45(\operatorname{SE} 0.11)^{\mathrm{b}}$ & $F(1,2351)=17.0$ & $<0.001$ \\
\hline model 2 & 1.97 (SE 0.08) & 1.89 (SE 0.08) & 2.07 (SE 0.12) & 2.30 (SE 0.10) & $F(1,2280)=6.7$ & 0.010 \\
\hline \multicolumn{7}{|l|}{ Apathy subscale: } \\
\hline Median $\left(P_{25}, P_{75}\right)$ & $1(0-1,1)$ & $1(0-2)$ & $1(0-2)$ & $1(0-2)$ & & \\
\hline crude & $0.88($ SE 0.03) & $0.98(\text { SE } 0.04)^{b}$ & $1.05(\mathrm{SE} 0.05)^{\mathrm{b}}$ & $1.26(\mathrm{SE} 0.05)^{\mathrm{c}}$ & $F(1,2351)=42.8$ & $<0.001$ \\
\hline Model 1 & $0.90(\text { SE } 0.04)^{a}$ & $0.99($ SE 0.03) & $1.04($ SE 0.05) & $1.21(\mathrm{SE} 0.05)^{\mathrm{b}}$ & $F(1,2335)=27.6$ & $<0.001$ \\
\hline model 2 & $0.93($ SE 0.04) & $0.99(\text { SE } 0.03)^{a}$ & $1.01(\mathrm{SE} 0.05)^{\mathrm{a}}$ & $1.16(\mathrm{SE} 0.05)^{\mathrm{b}}$ & $F(1,2280)=14.4$ & $<0.001$ \\
\hline \multicolumn{7}{|l|}{ Dispositional optimism: } \\
\hline Median $\left(P_{25}, P_{75}\right)$ & $7(6-8)$ & $7(6-8)$ & $6(5-8)$ & $6(5-7)$ & & \\
\hline crude & $6.46(\text { SE } 0.06)^{a}$ & $6.39\left(\right.$ SE 0.06) ${ }^{\mathrm{a}}$ & $6.16(\text { SE } 0.10)^{b}$ & $6.02(\mathrm{SE} 0.08)^{\mathrm{b}}$ & $F(1,2351)=24.9$ & $<0.001$ \\
\hline model 1 & 6.40 (SE 0.06) & 6.38 (SE 0.06) & 6.17 (SE 0.09) & 6.10 (SE 0.07) & $F(1,2335)=12.8$ & $<0.001$ \\
\hline model 2 & 6.37 (SE 0.06) & 6.38 (SE 0.06) & 6.18 (SE 0.09) & 6.16 (SE 0.07) & $F(1,2280)=6.8$ & 0.009 \\
\hline
\end{tabular}

Data are reported as (adjusted) mean and standard errors (SE)

Analysis of covariance (ANCOVA) was used to determine significance for linear trend over the 4 categories of eGFR and CRP levels

Model 1: adjusted for age, sex, education, and 4 randomized groups (using 3 dummy variables)

Model 2: additionally adjusted for body mass index, smoking status, alcohol use, antidepressant use, statin use, time since myocardial infarction, stroke and diabetes

abcd Superscript letters that are dissimilar indicate significant differences in post-hoc tests

\section{Discussion}

The present results show that kidney dysfunction (reflected by a lower eGFR) and systemic inflammation (reflected by a higher hs-CRP level) were independently associated with apathy in post-myocardial infarction patients. The associations with depressive symptoms and dispositional optimism were less robust. Kidney dysfunction showed a linear and somewhat stronger association for apathy than for systemic inflammation, for which there seemed to be a threshold value of $7 \mathrm{mg} / \mathrm{L}$.

We are not aware of previous studies that assessed the relation between kidney dysfunction and apathy symptoms in a large cohort. Nevertheless, our findings are in line with others reporting that patients with an eGFR $<$ $30 \mathrm{ml} / \mathrm{min} / 1.73 \mathrm{~m}^{2}$ had more depressive symptoms than patients with an eGFR $\geq 90 \mathrm{ml} / \mathrm{min} / 1.73 \mathrm{~m}^{2}$ [14-16]. We 
Table 3 Associations of creatinine-cystatin C-based eGFR and serum CRP level with depressive and apathy symptoms, and dispositional optimism in 2355 post-myocardial infarction patients

\begin{tabular}{|c|c|c|c|c|}
\hline & \multicolumn{4}{|c|}{ Depressive symptoms } \\
\hline & Crude & Model 1 & Model 2 & Model 3 \\
\hline \multirow[t]{3}{*}{ Creatinine-cystatin C-based eGFR } & -0.181 & -0.116 & -0.084 & -0.074 \\
\hline & $\mathrm{t}=-8.904$ & $t=-5.118$ & $t=-3.691$ & $t=-3.195$ \\
\hline & $p<0.001$ & $p<0.001$ & $p<0.001$ & $p=0.001$ \\
\hline \multirow[t]{5}{*}{ C-reactive protein levels } & 0.106 & 0.082 & 0.051 & 0.035 \\
\hline & $t=5.171$ & $t=4.017$ & $t=2.476$ & $t=1.650$ \\
\hline & $p<0.001$ & $p<0.001$ & $p=0.013$ & $p=0.099$ \\
\hline & \multicolumn{4}{|c|}{ Apathy subscale } \\
\hline & Crude & Model 1 & Model 2 & Model 3 \\
\hline \multirow[t]{3}{*}{ Creatinine-cystatin C-based eGFR } & -0.219 & -0.135 & -0.101 & -0.084 \\
\hline & $t=-10.879$ & $t=-6.002$ & $t=-4.440$ & $t=-3.598$ \\
\hline & $p<0.001$ & $p<0.001$ & $p<0.001$ & $p<0.001$ \\
\hline \multirow[t]{5}{*}{ C-reactive protein levels } & 0.137 & 0.110 & 0.083 & 0.065 \\
\hline & $t=6.696$ & $t=5.479$ & $t=3.999$ & $t=3.039$ \\
\hline & $p<0.001$ & $p<0.001$ & $p<0.001$ & $p=0.002$ \\
\hline & \multicolumn{4}{|c|}{ Dispositional optimism } \\
\hline & Crude & Model 1 & Model 2 & Model 3 \\
\hline \multirow[t]{3}{*}{ Creatinine-cystatin C-based eGFR } & 0.194 & 0.089 & 0.072 & 0.063 \\
\hline & $t=9.613$ & $t=3.979$ & $t=3.152$ & $t=2.693$ \\
\hline & $p<0.001$ & $p<0.001$ & $p=0.002$ & $p=0.007$ \\
\hline \multirow[t]{3}{*}{ C-reactive protein levels } & -0.094 & -0.065 & -0.047 & -0.033 \\
\hline & $t=-4.585$ & $t=-3.244$ & $t=-2.258$ & $t=-1.556$ \\
\hline & $p<0.001$ & $p=0.001$ & $p=0.024$ & $p=0.12$ \\
\hline
\end{tabular}

Data are beta-coefficients ( $p$-value) after linear regression analysis

CRP values were naturally log transformed before analysis because of a positively skewed distribution

Model 1: adjusted for age, sex, education, and 4 randomized groups (using 3 dummy variables)

Model 2: additionally adjusted for body mass index, smoking status, alcohol use, antidepressant use, statin use, time since myocardial infarction, stroke, and diabetes

Model 3: full model, additionally adjusted for the other possible predictors (Creatinine-cystatin C-based eGFR, or CRP levels)

extended these findings by showing that an increase in depressive symptoms was already present in patients with an eGFR $<60 \mathrm{ml} / \mathrm{min} / 1.73 \mathrm{~m}^{2}$ compared to those with a better eGFR. Low apathy was found within the normal range of kidney function. On the other hand, our results are in contrast to those of the only other large study on CHD patients $(n=967)$ that did not find more depressive symptoms in patients with an eGFR < $60 \mathrm{ml} / \mathrm{min} / 1.73 \mathrm{~m}^{2}$ compared to those with an eGFR of $\geq 60 \mathrm{ml} / \mathrm{min} / 1.73 \mathrm{~m}^{2}$ [18]. However, this latter study dichotomized kidney function at $<60 \mathrm{ml} / \mathrm{min} / 1.73 \mathrm{~m}^{2}$ which reduced the statistical power, and did not include CysC levels or apathy in their analyses. A study in a general population sample of over 28,000 individuals showed an inverse, linear trend relation between kidney function and depression, which did not persist in the multivariable model [14]; however, in that study depression was measured using the 4-item Center for Epidemiologic Studies Depression Scale during a telephone interview and, again, neither CysC levels nor apathy were assessed. We have extended these findings by showing a linear trend relation between eGFR and depressive symptoms, which was strongest for the apathy subscale.

Several mechanisms could be involved in the relation between kidney dysfunction and apathy. For example, the vascular apathy hypothesis is suggested to underlie the relation between vascular disease and apathy symptoms [24]. Atherosclerosis may have caused renal vascular disease resulting in poorer eGFR as well as cerebrovascular disease causing brain ischemia which may result in apathy. The accumulation of uremic toxins causes encephalopathy in patients with kidney failure [42]. In patients with less severe kidney impairment, the neurotoxic effect of the accumulation of uremic toxins might have resulted in less extreme symptoms of apathy. Furthermore, anemia is a well-known complication of chronic kidney disease and could be part of the causal pathway to apathy. Also, apathy symptoms might overlap with other symptoms that occur 

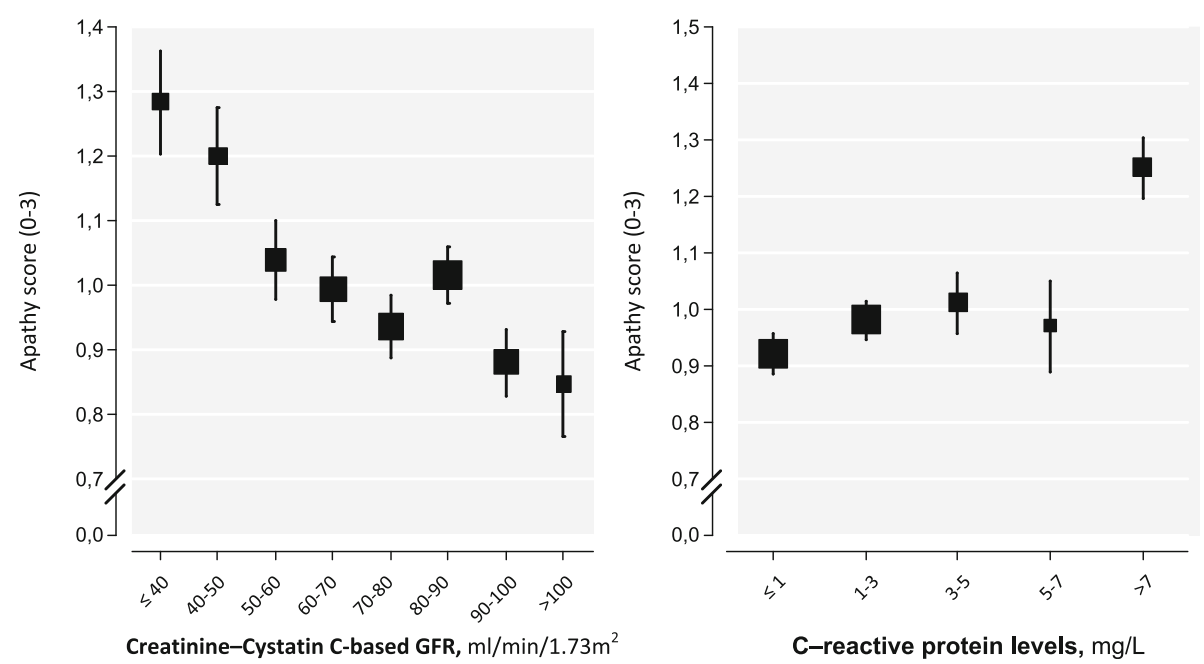

Fig. 1 Associations of the creatinine-cystatin C-based eGFR and serum CRP levels with apathy in 2355 post-myocardial infarction patients. Mean serum eGFR and CRP levels are shown with error bars representing standard errors (SE), adjusted for age, sex, education, body mass index, smoking status, alcohol use, antidepressant use, statin use, time since myocardial infarction, stroke, and diabetes. The box sizes represent the relative number of patients

in patients with kidney dysfunction. For example, fatigue shows some similarity with apathy and is one of the most frequently mentioned symptoms in patients with severe kidney dysfunction [43]. However, most studies on the relation between fatigue and psychological factors focused on depression and anxiety, but did not assess apathy. Finally, a third factor, related to aging, may underlie both apathy, inflammation and kidney dysfunction.

Earlier studies in CHD patients found no association between CRP levels and depressive symptoms [20, 23, 44]. However, the use of statins (and possibly beta-blockers and anti-depressants) may have reduced the inflammatory state [45-47] and thereby obscured the relation between CRP and depressive symptoms. In our study, however, an even higher proportion of patients used statins (87.7\%) than in these latter studies; moreover, our study sample was larger than that of earlier studies [20, 23, 44]. Our findings are in line with the results of a large meta-analysis which also found that higher CRP levels were associated with more depressive symptoms in healthy individuals [19]. Also, for CRP levels we found that the strongest association was with the apathy subscale. Eurlings et al. found a concomitant relation between inflammation and apathy symptoms, and suggested that apathy symptoms may be part of sickness behavior, which can be described as a motivational state that reorganizes the organism's priorities to cope with systemic inflammation and infectious disease [29]. Kidney dysfunction may have caused a higher systemic inflammatory state [8] which, in turn, resulted in more apathy. However, this hypothesis was only partly supported by our results which show that the relation between eGFR and apathy symptoms is largely independent of CRP levels.
As opposed to depressive symptoms, optimism has been associated with better health outcomes (such as survival) in CHD patients and the general population [48-51]. Both behavioral (e.g. healthy diet, physical activity, and nonsmoking) and biological pathways have been suggested as mechanistic explanations. In CHD patients we found a significant relation between eGFR and dispositional optimism, and an inverse relation between CRP levels and dispositional optimism. Other studies found no relation between CRP and optimism or other measures of positive affect, but did find an inverse relation with other markers of inflammation, such as interleukin 6 (IL-6) and tumor necrosis factor alpha (TNF- $\alpha$ ) [52-54].

Some limitations of the present study need to be addressed. First, because psychological measures were assessed at 40 months only, we were unable to address potential temporal relations. Second, because our cohort consisted of post-myocardial infarction patients, the results cannot be extrapolated to other populations. Third, depressive symptoms were assessed using a questionnaire with 15 relatively crude 'yes/no' answer categories. Fourth, because we lacked information on proteinuria or hematuria we could not distinguish between the presence or absence of chronic kidney disease in patients with an eGFR of $60-89 \mathrm{ml} / \mathrm{min} / 1.73 \mathrm{~m}^{2}$.

However, our study also has several strengths. The study had a large enough sample size to detect small but significant effects. Moreover, we used the combined creatinineCysC-based CKD-EPI equation to estimate the eGFR, which is considered more accurate than creatinine-based eGFR [31]. Also, use of the GDS-15 to assess depressive symptoms excluded certain somatic symptoms which might be due to medical illness in elderly medical patients 
[35]. Finally, it has been shown in cardiac patients that, compared with the Beck Depression Inventory (BDI) I and II, the GDS was better able to differentiate between those who are depressed and those who are not depressed [55].

\section{Conclusion}

In conclusion, the present study shows a significant independent association between kidney dysfunction and apathy in post-myocardial infarction patients. This association was already apparent within the mild kidney dysfunction range. This implies that, at the population level, the impact of kidney dysfunction on mental wellbeing may be large, since we found that $26 \%$ of postmyocardial patients suffer from kidney dysfunction (eGFR $<60 \mathrm{ml} / \mathrm{min} / 1.73 \mathrm{~m}^{2}$ ).

\section{Abbreviations}

4Q: 4-item Optimism Questionnaire; CHD: Coronary heart disease; CKD: Chronic kidney disease; CRP: C-reactive protein; CysC: Cystatin C; eGFR: Estimated glomerular filtration rate; ESRD: End stage renal disease: GDS-15: 15-item Geriatric Depression Scale; hs-CRP: High-sensitivity CRP; MDD: Major depressive disorder

\section{Acknowledgements}

Not applicable.

\section{Funding}

Not applicable.

\section{Availability of data and materials}

All data supporting the study are presented in the manuscript or are available on request from the corresponding author (R.H.M. Heeres).

\section{Authors' contributions \\ Substantial contributions to conception and design, or acquisition of data, or analysis and interpretation of data: RHMH, EKH, JMG, JG, DK, EJG; drafting the manuscript or revising it critically for important intellectual content: $\mathrm{RHMH}$, EKH, JMG, JG, DK, EJG; final approval of the version to be published: RHMH, EKH, JMG, JG, DK, EJG; and agree to be accountable for all aspects of the work in ensuring that questions related to the accuracy or integrity of any part of the work are appropriately investigated and resolved: RHMH, EKH, JMG, JG, DK, EJG. Each author participated sufficiently in the work to take public responsibility for appropriate portions of the content. All authors read and approved the final manuscript.}

\section{Authors' information}

Not applicable.

\section{Competing interests}

The authors declare that they have no competing interests.

\section{Consent for publication}

Not applicable.

\section{Ethics approval and consent to participate}

The Alpha Omega Trial was conducted in accordance with the Declaration of Helsinki and was approved by a central Medical Ethics Committee in the Netherlands (Haga Hospital, Leyenburg, The Hague, Netherlands, Office for Human Research Protections \#IORG0004004) and by the committees of all participating hospitals. Written informed consent was obtained from all patients.

\section{Author details}

'Department of Psychiatry, Leiden University Medical Center, Postbus 9600, 2300, RC, Leiden, Netherlands. ${ }^{2}$ Departments of Internal Medicine and Nephrology, Jeroen Bosch Hospital, Den Bosch, Netherlands. ${ }^{3}$ Division of Human Nutrition, Wageningen University, Wageningen, Netherlands.
Received: 14 September 2016 Accepted: 20 December 2016

Published online: 12 January 2017

\section{References}

1. Nicholson A, Kuper H, Hemingway H. Depression as an aetiologic and prognostic factor in coronary heart disease: A meta-analysis of 6362 events among 146538 participants in 54 observational studies. Eur Heart J. 2006; 27:2763-74.

2. Thombs BD, Bass EB, Ford DE, Stewart KJ, Tsilidis KK, Patel U, et al. Prevalence of depression in survivors of acute myocardial infarction. $J$ Gen Intern Med. 2006;21:30-8.

3. Bhatt $\mathrm{H}$, Safford M, Glasser S. Coronary heart disease risk factors and outcomes in the twenty-first century: Findings from the reasons for geographic and racial differences in stroke (regards) study. Curr Hypertens Rep. 2015;17:1-20.

4. Lichtman JH, Froelicher ES, Blumenthal JA, Carney RM, Doering LV, FrasureSmith $\mathrm{N}$, et al. Depression as a risk factor for poor prognosis among patients with acute coronary syndrome: Systematic review and recommendations a scientific statement from the american heart association. Circulation. 2014:129:1350-69

5. Zuidersma M, Conradi HJ, van Melle JP, Ormel J, de Jonge P. Selfreported depressive symptoms, diagnosed clinical depression and cardiac morbidity and mortality after myocardial infarction. Int J Cardiol. 2013;167:2775-80.

6. Lane D, Carroll D, Ring C, Beevers DG, Lip GY. In-hospital symptoms of depression do not predict mortality 3 years after myocardial infarction. Int J Epidemiol. 2002;31:1179-82.

7. Kimmel PL, Cukor D, Cohen SD, Peterson RA. Depression in end-stage renal disease patients: A critical review. Adv Chronic Kidney Dis. 2007;14:328-34.

8. Silverstein DM. Inflammation in chronic kidney disease: role in the progression of renal and cardiovascular disease. Pediatr Nephrol. 2009;24:1445-52.

9. Poole L, Dickens C, Steptoe A. The puzzle of depression and acute coronary syndrome: reviewing the role of acute inflammation. J Psychosom Res. 2011;71:61-8.

10. Liuzzo G, Biasucci LM, Gallimore JR, Grillo RL, Rebuzzi AG, Pepys MB, et al. The prognostic value of c-reactive protein and serum amyloid a protein in severe unstable angina. N Engl J Med. 1994;331:417-24.

11. Lindahl B, Toss H, Siegbahn A, Venge P, Wallentin L. Markers of myocardial damage and inflammation in relation to long-term mortality in unstable coronary artery disease. N Engl J Med. 2000;343:1139-47.

12. Miyamoto T, Carrero JJ, Stenvinkel P. Inflammation as a risk factor and target for therapy in chronic kidney disease. Curr Opin Nephrol Hypertens. 2011;20:662-8.

13. Hansson GK. Inflammation, atherosclerosis, and coronary artery disease. N Engl J Med. 2005;352:1685-95.

14. McClellan WM, Abramson J, Newsome B, Temple E, Wadley VG, Audhya P, et al. Physical and psychological burden of chronic kidney disease among older adults. Am J Nephrol. 2010;31:309-17.

15. Campbell KH, Huang ES, Dale W, Parker MM, John PM, Young BA, et al. Association between estimated gfr, health-related quality of life, and depression among older adults with diabetes: the diabetes and aging study. Am J Kidney Dis. 2013;62:541-8.

16. Ricardo AC, Fischer MJ, Peck A, Turyk M, Lash JP. Depressive symptoms and chronic kidney disease: results from the national health and nutrition examination survey (nhanes) 2005-2006. Int Urol Nephrol. 2010;42:1063-8,

17. Hedayati SS, Jiang W, O'Connor CM, Kuchibhatla M, Krishnan KR, Cuffe MS, et al. The association between depression and chronic kidney disease and mortality among patients hospitalized with congestive heart failure. Am J Kidney Dis. 2004;44:207-15.

18. Odden MC, Whooley MA, Shlipak MG. Depression, stress, and quality of life in persons with chronic kidney disease: the heart and soul study. Nephron Clin Pract. 2006;103:c1-7.

19. Howren MB, Lamkin DM, Suls J. Associations of depression with c-reactive protein, il-1, and il-6: a meta-analysis. Psychosom Med. 2009;71:171-86.

20. Whooley MA, Caska CM, Hendrickson BE, Rourke MA, Ho J, Ali S. Depression and inflammation in patients with coronary heart disease: findings from the heart and soul study. Biol Psychiatry. 2007;62:314-20.

21. Annique S, Dorien T, Richel L, Gunter K, Joris D, Harry JC, et al. Inflammatory markers in depressed post-myocardial infarction patients. J Psychiatr Res. 2005;39:137-44 
22. Bankier B, Barajas J, Martinez-Rumayor A, Januzzi JL. Association between major depressive disorder and c-reactive protein levels in stable coronary heart disease patients. J Psychosom Res. 2009;66:189-94.

23. Mommersteeg PM, Meeuwis SH, Denollet J, Widdershoven JW, Aarnoudse W, Westerhuis $B L$, et al. C-reactive protein and fibrinogen in non-obstructive coronary artery disease as related to depressive symptoms and anxiety: Findings from the tweesteden mild stenosis study (twist). J Psychosom Res. 2014;77:426-9.

24. Van der Mast R, Vinkers D, Stek M, Bek M, Westendorp R, Gussekloo J, et al. Vascular disease and apathy in old age. The Leiden 85-plus study. Int J Geriatr Psychiatry. 2008;23:266-71.

25. Ligthart SA, Richard E, Fransen NL, Eurelings LS, Beem L, Eikelenboom P, et al. Association of vascular factors with apathy in community-dwelling elderly individuals. Arch Gen Psychiatry. 2012;69:636-42.

26. Eurelings LS, Ligthart SA, Dalen JW, Moll van Charante EP, Gool WA, Richard E. Apathy is an independent risk factor for incident cardiovascular disease in the older individual: a population-based cohort study. Int J Geriatr Psychiatry. 2014;29:454-63.

27. Marin RS. Apathy: a neuropsychiatric syndrome. J Neuropsychiatry Clin Neurosci. 1991;3:243-54.

28. Maas $D$, Van der Mast $R$, de Craen A. Increased c-reactive protein is not associated with apathy: the Leiden 85-plus study. Int J Geriatr Psychiatry. 2009;24:1177-84.

29. Eurelings LS, Richard E, Eikelenboom P, van Gool WA, Moll van Charante EP. Low-grade inflammation differentiates between symptoms of apathy and depression in community-dwelling older individuals. Int Psychogeriatr. 2015;27:639-47.

30. Scheier MF, Carver CS, Bridges MW. Distinguishing optimism from neuroticism (and trait anxiety, self-mastery, and self-esteem): a reevaluation of the life orientation test. JPersSoc Psychol. 1994;67:1063-78.

31. Inker LA, Schmid CH, Tighiouart H, Eckfeldt JH, Feldman HI, Greene T, et al. Estimating glomerular filtration rate from serum creatinine and cystatin c. N Engl J Med. 2012;367:20-9.

32. Geleijnse JM, Giltay EJ, Schouten EG, de Goede J, Griep LMO, TeitsmaJansen AM, et al. Effect of low doses of n-3 fatty acids on cardiovascular diseases in 4,837 post-myocardial infarction patients: design and baseline characteristics of the alpha omega trial. Am Heart J. 2010;159:539-46.

33. Kromhout D, Giltay EJ, Geleijnse JM. N-3 fatty acids and cardiovascular events after myocardial infarction. N Engl J Med. 2010;363:2015-26.

34. D'ATH P, Katona P, Mullan E, Evans S, Katona C. Screening, detection and management of depression in elderly primary care attenders. I: The acceptability and performance of the 15 item geriatric depression scale (gds15) and the development of short versions. Fam Pract. 1994;11:260-6.

35. Pomeroy IM, Clark CR, Philp I. The effectiveness of very short scales for depression screening in elderly medical patients. Int J Geriatr Psychiatry. 2001;16:321-6.

36. Starkstein SE, Mayberg HS, Preziosi T, Andrezejewski P, Leiguarda R, Robinson R. Reliability, validity, and clinical correlates of apathy in parkinson's disease. J Neuropsychiatry Clin Neurosci. 1992;4:134-9.

37. Giltay EJ, Kamphuis MH, Kalmijn S, Zitman FG, Kromhout D. Dispositional optimism and the risk of cardiovascular death: the zutphen elderly study. Arch Intern Med. 2006;166:431-6.

38. Giltay EJ, Geleijnse JM, Schouten EG, Katan MB, Kromhout D. High stability of markers of cardiovascular risk in blood samples. Clin Chem. 2003;49:652-5.

39. Grubb A, Blirup-Jensen S, Lindström V, Schmidt C, Althaus H, Zegers I. First certified reference material for cystatin c in human serum erm-da471/ifcc. Eur J Clin Chem Clin Biochem. 2010;48:1619-21.

40. Levey AS, Coresh J, Balk E, Kausz AT, Levin A, Steffes MW, et al. National kidney foundation practice guidelines for chronic kidney disease: evaluation, classification, and stratification. Ann Intern Med. 2003;139:137-47.

41. Ridker PM, Rifai N, Rose L, Buring JE, Cook NR. Comparison of c-reactive protein and low-density lipoprotein cholesterol levels in the prediction of first cardiovascular events. N Engl J Med. 2002;347:1557-65.

42. Seifter JL, Samuels MA. Uremic encephalopathy and other brain disorders associated with renal failure. Semin Neurol. 2011;31:139-43.

43. Curtin RB, Bultman DC, Thomas-Hawkins C, Walters BA, Schatell D. Hemodialysis patients' symptom experiences: effects on physical and mental functioning. ANNA J. 2002;29:562-74.

44. Steptoe A, Wikman A, Molloy GJ, Messerli-Bürgy N, Kaski J-C. Inflammation and symptoms of depression and anxiety in patients with acute coronary heart disease. Brain Behav Immun. 2013;31:183-8.
45. Ridker P. Should statin therapy be considered for patients with elevated c-reactive protein? the need for a definitive clinical trial. Eur Heart J. 2001;22:2135-7.

46. Kenis G, Maes M. Effects of antidepressants on the production of cytokines. Int J Neuropsychopharmacol. 2002;5:401-12.

47. Lanza GA, Pitocco D, Navarese EP, Sestito A, Sgueglia GA, Manto A, et al. Association between cardiac autonomic dysfunction and inflammation in type 1 diabetic patients: effect of beta-blockade. Eur Heart J. 2007;28:814-20.

48. Scheier MF, Matthews KA, Owens JF, Magovern GJ, Lefebvre RC, Abbott RA, et al. Dispositional optimism and recovery from coronary artery bypass surgery: the beneficial effects on physical and psychological well-being. J Pers Soc Psychol. 1989;57:1024-40.

49. Scheier MF, Matthews KA, Owens JF, Schulz R, Bridges MW, Magovern GJ, et al. Optimism and rehospitalization after coronary artery bypass graft surgery. Arch Intern Med. 1999;159:829-35.

50. Leedham B, Meyerowitz BE, Muirhead J, Frist WH. Positive expectations predict health after heart transplantation. Health Psychol. 1995;14:74-9.

51. Agarwal M, Dalal A, Agarwal D, Agarwal R. Positive life orientation and recovery from myocardial infarction. Soc Sci Med. 1995;40:125-30.

52. Roy B, Diez-Roux AV, Seeman T, Ranjit N, Shea S, Cushman M. The association of optimism and pessimism with inflammation and hemostasis in the multiethnic study of atherosclerosis (MESA). Psych Med. 2010;72:134-40.

53. Ikeda A, Schwartz J, Peters JL, Fang S, Spiro III A, Sparrow D, et al. Optimism in relation to inflammation and endothelial dysfunction in older men: the va normative aging study. Psych Med. 2011;73:664-71.

54. Brouwers C, Mommersteeg PM, Nyklíček I, Pelle AJ, Westerhuis BL, Szabó BM, et al. Positive affect dimensions and their association with inflammatory biomarkers in patients with chronic heart failure. Biol Psychol. 2013;92:220-6.

55. Low GD, Hubley AM. Screening for depression after cardiac events using the beck depression inventory-ii and the geriatric depression scale. Soc Indic Res. 2007;82:527-43.

\section{Submit your next manuscript to BioMed Central and we will help you at every step:}

- We accept pre-submission inquiries

- Our selector tool helps you to find the most relevant journal

- We provide round the clock customer support

- Convenient online submission

- Thorough peer review

- Inclusion in PubMed and all major indexing services

- Maximum visibility for your research

Submit your manuscript at www.biomedcentral.com/submit
C Biomed Central 